\title{
Extending the UCP Model by Incorporating the Prevailing Trends in Software Effort Estimation
}

\author{
M Usman Habib \\ Software Engineer \\ Central Depository Company of \\ Pakistan
}

\author{
M Asim Ali \\ Assistant Professor \\ Dept of Computer Science \\ FAST - NUCES, Karachi
}

\author{
Nauman Atique \\ Assistant Professor \\ Dept of Computer Science \\ FAST - NUCES, Karachi
}

\begin{abstract}
The research work is an extension of the original UCP Model for software estimation by incorporating the factors that are currently weighted in estimation of software by IT professionals. The rationale of the study is to make UCP Model effective, realistic and more accurate for the current IT industry. To identify the gap between the original UCP model and the current estimation considerations, a survey was conducted and the results of the survey were used to extend the model.
\end{abstract}

\section{General Terms}

Software Estimation, Use Case Point estimation.

\section{Keywords}

Software Estimation, Use Case Point, measurement, Pakistan.

\section{INTRODUCTION}

Use Cases have become a standard artifact to representation software requirements and based on Use Cases, Karner formulated UCP (Use Case Points) Model [2] for software estimation. Although there exists other estimation models e.g. FP and COCOMO [5] but they are based on lines of code rather the project requirements and therefore were applicable only to procedural paradigm. The idea of UCP was presented to estimate software developed using Object Oriented paradigm [2]. Since software products are currently being developed using object oriented paradigm and procedural languages are now rarely used, therefore, considering the practicality of implementation of projects in object oriented languages the authors chose UCP model for the study. However the original UCP presented by [3] has become obsolete as it does not consider the trends and practices of the current IT industry. Hence, to make UCP model a better fit for current IT industry the authors extend the original UCP model.

\section{ISSUES AND PROBLEMS}

The original UCP model was proposed in 1993 [1] and there have been efforts by other researchers to improve the UCP model from different perspectives using different approaches [6]. However there is a need to revamp the original UCP model for its affective use and applicability for projects that are undertaken by the IT industry with recent considerations not only with respect to technology and the environment but also in accordance with the project classification and work items (use cases and reports).

As UCP model is rightly based on a defined set of technical and environmental factors but some of the technical and environmental factors, considered by IT professionals of recent times, are not addressed by the original UCP model. Hence the authors addressed the need of extending the UCP by extending the set of technical and environmental factors with the prevailing trends. Moreover the difference in the estimation mechanism between reports and Use cases; and difference in calculating the estimation effort based on project classification is also addressed.

Hence, the four problem areas addressed are listed as follows:

a) Prevailing Technical Factors affecting the Estimation [2]

b) Prevailing Environmental Factors affecting the Estimation [2]

c) Differentiating estimation of Reports from Use Cases

d) Estimating the Project Effort based on Project Classification (along with UCP)

\section{APPROACHES AND METHODS}

A survey was conducted as part of the study to identify the technical and environmental factors and their affect on the estimation. The survey was also used to identify the complexity level of the reports based on their description and the need to differentiate estimation of reports from use cases.

Also a formula has also been inferred from the effort estimation formula of COCOMO [5] to accommodate the project classification attribute in context of UCP.

Finally a methodology for extended UCP model is proposed by consolidating the above two approaches.

\section{CONDUCTING THE QUESTIONNAIRE SURVEY}

Because recent trends in software estimation could only be identified from IT professionals working in the IT industry, therefore a questionnaire based survey was prepared and distributed to the IT professionals.

Seven steps process defined in the SEI Guideline of Survey Design [3] was followed. Below is the seven-step survey process that was followed with related information:

1) Identify the research objectives - Potential improvements in estimation in context of UCP model.

2) Identify and characterize the target audience - IT professionals with insight of software estimation.

3) Design the sampling plan - IT professionals of diversified experiences in the industry, across different organizations, in different countries were focused.

4) Design and write the questionnaire - All of the survey questions are close-ended, in order to make it easier to be completed within limited time.

5) Pilot test the questionnaire - The initial draft of survey was distributed to limited set of people to get feedback for improvement. The feedback was incorporated and finalized survey was devised. 
6) Distribute the questionnaire - The survey was distributed to the audience in two ways:

a) Emailing the Electronic Survey Form (Word Document)

b) A web based version of the survey form was prepared and URL shared with the IT professionals who submitted their responses to the survey - $\quad$ URL: https://spreadsheets.google.com/spreadsheet/vi ewform?formkey=dExFMnFhRmZISmluXzJ3 N31FYThyUlE6MQ

7) Analyze the results and write report - In total, there were 38 respondents of 23 organizations, from 8 countries, with many organizations with software process improvement under CMM, CMMI [8] or ISO-9000 standards [7]. The average experience of the respondents was 8 years.

In total seven questions were asked in the survey to facilitate four areas of consideration, identified earlier.

\subsection{Prevailing Technical Factors Affecting the Estimation}

From the survey two questions were asked to identify the technical factors and their respective impact, which are considered current estimation.

First question was asked to identify the impact of the following factors for increase in estimation - i.e. factors that may contribute to increase the project development effort:
a) Technological Risks in the project
b) Multilingual Support in the project
c) Integration with other systems
d) Scalability requirements
e) Required Software Reliability (e.g. Space shuttle, satellite operations etc.)
f) Documentation (of code and other technical artifacts)
g) Development of Unit Test Cases for unit testing

Second question was asked to identify the impact of the following factors for decrease in estimation-i.e. factors that may contribute to decrease the project development effort:

a) Use of Third Party API / Pre-build components (e.g. Reporting Engine - Crystal Report, MS Reporting Services, JReport etc. Data Access Layer e.g. Hibernate etc.)

b) IDE (Integrated Development Environment) supporting automatic code generation and/or automatic code introspection

c) User of Automated testing tool for testing (reducing testing cycles time)

Each of the factors listed above were rated by survey respondents on the basis of set of ratings - Very High, High, Nominal, Low, Not Applicable.

\subsection{Prevailing Environmental Factors Affecting the Estimation}

From the survey two questions were asked to identify the environmental factors and their respective impact, which are considered current estimation.
First question was asked to identify the impact of the following factors for increase in estimation - i.e. factors that may contribute to increase the project development effort:

a) Lack of stakeholder (sponsor, subcontractor etc.) collaboration

b) Distractions for the Development Team (Facebook, Twitter, YouTube, Emails, Online News / Stocks, Blogging, Network Games, Online Games, Gossiping etc.)

c) Geographically Dislocated team

Second question was asked to identify the impact of the following factors for decrease in estimation- i.e. factors that may contribute to decrease the project development effort:

a) Project Manager's Capability

b) $\mathrm{CMM} / \mathrm{CMMi}$ compliance level of the organization

c) Testing team's experience with testing tools \& methodologies

d) Testing team's experience with the application / project domain

Each of the factors listed above were rated by survey respondents on the basis of set of ratings - Very High, High, Nominal, Low, Not Applicable

\subsection{Differentiating Estimation of Report from Use Cases}

From the survey two questions were asked. First question was asked to identify the complexity of reports on a scale of 1 to 10 - with 10 being the most complex. Following are the most common types of reports for which were rated by the survey respondents.

a) Report based on query from one entity only

b) Report based on query from two or more entities (table join) only

c) Report based on query with table joins along with inner queries

d) Report based on query with table joins along with calls to one or more user defined database function / stored procedure

e) Report based on query with recurring function (due to recurring dependency of records i.e. each record has a Foreign Key reference to the table itself)

In second question respondents were asked if they agree with the notion that reports should be estimated differently from use cases - 'Yes' and 'No' were the only two options available.

\subsection{Estimating the Project Effort Based on Project Classification by COCOMO}

Respondents were asked if they agree that the project classification used by COCOMO [5] (based on lines of code procedural languages) for effort estimation may also be used for estimating projects that are developed using object oriented languages - 'Yes' and 'No' were the only two options available. 


\section{ANALYSIS AND DERIVED DATA}

\subsection{Prevailing Technical and}

\section{Environmental Factors Affecting the}

\section{Estimation}

For the first four questions that required rating of technical and environment factors for increased and/or decreased estimation from the set of ratings ('Very High', 'High', 'Nominal', 'Low', 'Not Applicable'); the set of ratings were converted to numerals for data analysis and deduction of results.

\section{Table 1: Conversion of response ratings to numerals}

\begin{tabular}{|l|l|}
\hline Answer Option & Value \\
\hline Very High & 4 \\
\hline High & 3 \\
\hline Nominal & 2 \\
\hline Low & 1 \\
\hline Not Applicable & 0 \\
\hline
\end{tabular}

Converting the respondents' ratings to corresponding numerals, the average of values of the respondents' responses, for Prevailing Technical Factors that should be considered for increased estimates (Ti) were calculated to be as follows:

Table 2: Technical Factors for increased estimates - Ti

\begin{tabular}{|c|c|c|}
\hline & $\begin{array}{lc}\text { Technical Factors } & \text { for } \\
\text { increased estimates }-\mathrm{Ti} & \end{array}$ & Value \\
\hline a. & $\begin{array}{l}\text { Technological Risks in the } \\
\text { project }\end{array}$ & 2.74 \\
\hline b. & $\begin{array}{l}\text { Multilingual Support in the } \\
\text { project }\end{array}$ & 2.05 \\
\hline c. & Integration with other systems & 2.95 \\
\hline d. & Scalability requirements & 2.71 \\
\hline e. & $\begin{array}{l}\text { Required Software Reliability } \\
\text { (e.g. Space shuttle, satellite } \\
\text { operations etc.) }\end{array}$ & 2.32 \\
\hline f. & $\begin{array}{l}\text { Documentation (of code and } \\
\text { other technical artifacts) }\end{array}$ & 2.08 \\
\hline g. & $\begin{array}{l}\text { Development of Unit Test Cases } \\
\text { for unit testing }\end{array}$ & 1.92 \\
\hline
\end{tabular}

Converting the respondents' ratings to corresponding numerals, the average of values of the respondents' responses, for Prevailing Technical Factors that should be considered for decreased estimates ( $\mathrm{Td}$ ) were calculated to be as follows:
Table 3: Technical Factors for decreased estimates - Td

\begin{tabular}{|l|l|l|}
\hline & $\begin{array}{l}\text { Technical Factors for } \\
\text { decreased estimates - Td }\end{array}$ & Value \\
\hline a. & $\begin{array}{l}\text { Use of Third Party API / Pre- } \\
\text { build components (e.g. } \\
\text { Reporting Engine - Crystal } \\
\text { Report, MS Reporting Services, } \\
\text { JReport etc. Data Access Layer } \\
\text { e.g. Hibernate etc.) }\end{array}$ & 2.79 \\
\hline b. & $\begin{array}{l}\text { IDE (Integrated Development } \\
\text { Environment) supporting } \\
\text { automatic code generation } \\
\text { and/or automatic code } \\
\text { introspection }\end{array}$ & 2.29 \\
\hline c. & $\begin{array}{l}\text { User of Automated testing tool } \\
\text { for testing (reducing testing } \\
\text { cycles time) }\end{array}$ & 2.11 \\
\hline
\end{tabular}

Converting the respondents' ratings to corresponding numerals, the average of values of the respondents' responses, for Prevailing Environmental Factors that should be considered for increased estimates (Ei) were calculated to be as follows:

Table 4: Environmental Factors for increased estimates Ei

\begin{tabular}{|l|l|l|l|}
\hline & $\begin{array}{l}\text { Environmental Factors for } \\
\text { increased estimates - Ei }\end{array}$ & Value \\
\hline a. & $\begin{array}{l}\text { Lack of stakeholder (sponsor, } \\
\text { subcontractor etc.) } \\
\text { collaboration }\end{array}$ & 2.95 \\
\hline b. & $\begin{array}{l}\text { Distractions for the } \\
\text { Development Team (Facebook, } \\
\text { Twitter, YouTube, Emails, } \\
\text { Online News / Stocks, } \\
\text { Blogging, Network Games, } \\
\text { Online Games, Gossiping etc.) }\end{array}$ & \\
\hline c. & Geographically Dislocated team & 2.42 \\
\hline
\end{tabular}

Converting the respondents' ratings to corresponding numerals, the average of values of the respondents' responses, for Prevailing Environmental Factors that should be considered for decreased estimates (Ed) were calculated to be as follows:

Table 5: Environmental Factors for increased estimates Ed

\begin{tabular}{|l|l|l|}
\hline & $\begin{array}{l}\text { Environmental Factors for } \\
\text { decreased estimates - Ed }\end{array}$ & Value \\
\hline a. & Project Manager's Capability & 3.16 \\
\hline b. & $\begin{array}{l}\text { CMM / CMMi compliance level of the } \\
\text { organization }\end{array}$ & 1.5 \\
\hline c. & $\begin{array}{l}\text { Testing team's experience with testing } \\
\text { tools \& methodologies }\end{array}$ & 2.24 \\
\hline d. & $\begin{array}{l}\text { Testing team's experience with the } \\
\text { application / project domain }\end{array}$ & 2.53 \\
\hline
\end{tabular}


As all the values of Ti, Td, Ei and Ed were evaluated against the same scale therefore all the values were plotted in increasing order of values of technical and environmental factors over different types of graph for analysis.

Figure 1: Bar Chart - Technical and Environmental Factors

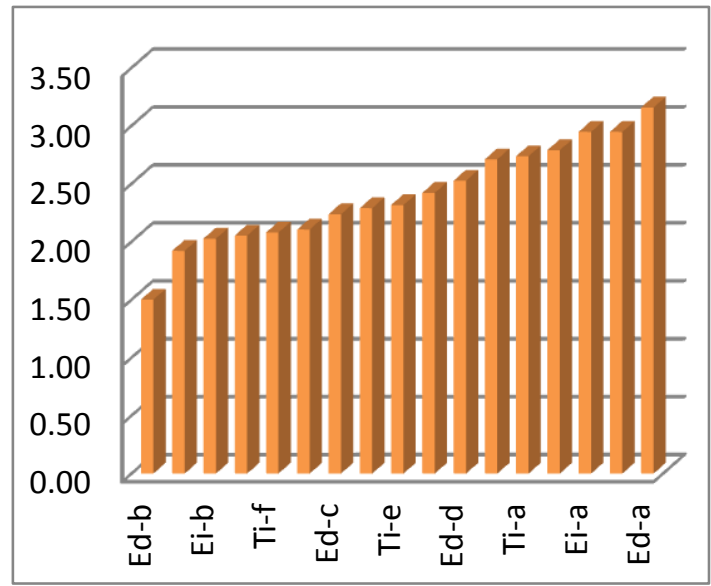

All the three graph view shows that there is a sharp drop in the graph for values under 2, therefore all the values that fall under 2 are pruned from the analysis - this is to ensure that insignificant (low value and sharp decrease in curve) factors aren't introduced to the UCP model and cause errors. As a matter of fact, even an insignificant factor would have a very high probability $(37 / 38=0.97)$ of having a value of greater than zero - thus pruning the values greater than zero but less than 2 makes sense.

Table 6: Technical and Environmental Factors and their Values in increasing order

\begin{tabular}{|l|l|l|}
\hline & Factors & Values \\
\hline 1. & Ed-b & 1.50 \\
\hline 2. & Ti-g & 1.92 \\
\hline 3. & Ei-b & 2.03 \\
\hline 4. & Ti-b & 2.05 \\
\hline 5. & Ti-f & 2.08 \\
\hline 6. & Td-c & 2.11 \\
\hline 7. & Ed-c & 2.24 \\
\hline 8. & Td-b & 2.29 \\
\hline 9. & Ti-e & 2.32 \\
\hline 10. & Ei-c & 2.42 \\
\hline 11. & Ed-d & 2.53 \\
\hline 12. & Ti-d & 2.71 \\
\hline 13. & Ti-a & 2.74 \\
\hline 14. & Td-a & 2.79 \\
\hline 15. & Ti-c & 2.95 \\
\hline 16. & Ei-a & 2.95 \\
\hline 17. & Ed-a & 3.16 \\
\hline & & \\
\hline
\end{tabular}

Table 7

Now, we have the minimum value 2.03 (say V-min) and maximum value 3.16 (say V-max). Again it should be noted that the value of $\mathrm{V}$-max would almost always be less than 4 (the max possible value).

Another, interesting fact to note is that the set of values for all the Technical and Environmental factors could be graded into 4 grades for each factors based on possible weights along with the impact of the factors in the survey.

With four bands of impact and the weight factors for technical and environmental factors, the minimum ( $\mathrm{V}$-min) and maximum $(\mathrm{V}-\max )$ values for factors are used to define 4 bands that could correspond to the 4 impact grades and corresponding weights of factors.

Table 8: Factor Impact Band and Factor Weights

\begin{tabular}{|l|l|l|l|l|l|}
\hline Impact of Factor & $\begin{array}{l}\text { Weights } \\
\text { for Ti }\end{array}$ & $\begin{array}{l}\text { Weights } \\
\text { for Td }\end{array}$ & $\begin{array}{l}\text { Weights } \\
\text { for Ei }\end{array}$ & $\begin{array}{l}\text { Weights } \\
\text { for Ed }\end{array}$ & Value Band \\
\hline Very High & 2 & -1 & -1 & 2 & $>=2.88$ and $<=3.16$ \\
\hline High & 1.5 & -0.75 & -0.75 & 1.5 & $>=2.60$ and $<2.88$. \\
\hline Nominal & 1 & -0.5 & -0.5 & 1 & $>=2.31$ and $<2.60$ \\
\hline Low & 0.5 & -0.25 & -0.25 & 0.5 & $>=2.03$ and $<2.31$ \\
\hline
\end{tabular}


Table 9: Prevailing Factors with Impact Weights for UCP

\begin{tabular}{|c|c|c|c|c|}
\hline & $\begin{array}{l}\text { Factor } \\
\text { Code }\end{array}$ & Factor & Values & Weight \\
\hline 1. & Ti-a & Technological Risks in the project & 2.74 & 1.5 \\
\hline 2. & Ti-b & Multilingual Support in the project & 2.05 & 0.5 \\
\hline 3. & Ti-c & Integration with other systems & 2.95 & 2 \\
\hline 4. & Ti-d & Scalability requirements & 2.71 & 1.5 \\
\hline 5. & Ti-e & Required Software Reliability & 2.32 & 1 \\
\hline 6. & Ti-f & Documentation (of code and other technical artifacts) & 2.08 & 0.5 \\
\hline 7. & Ti-g & Development of Unit Test Cases for unit testing & 1.92 & (N/A) \\
\hline 8. & Td-a & Use of Third Party API / Pre-build components & 2.79 & -0.75 \\
\hline 9. & Td-b & $\begin{array}{l}\text { IDE (Integrated Development Environment) supporting automatic code } \\
\text { generation and/or automatic code introspection }\end{array}$ & 2.29 & -0.25 \\
\hline 10. & Td-c & User of Automated testing tool for testing & 2.11 & -0.25 \\
\hline 11. & Ei-a & Lack of stakeholder (sponsor, subcontractor etc.) collaboration & 2.95 & -1 \\
\hline 12. & Ei-b & Distractions for the Development Team & $\mathbf{2 . 0 3}$ & -0.25 \\
\hline 13. & Ei-c & Geographically Dislocated team & 2.42 & -0.5 \\
\hline 14. & Ed-a & Project Manager's Capability & 3.16 & 2 \\
\hline 15. & $E d-b$ & CMM / CMMi compliance level of the organization & 1.5 & $(\mathrm{~N} / \mathrm{A})$ \\
\hline 16. & Ed-c & Testing team's experience with testing tools \& methodologies & 2.24 & 0.5 \\
\hline 17. & Ed-d & Testing team's experience with the application / project domain & 2.53 & 1 \\
\hline
\end{tabular}

Table 10: New Set of Technical Factors

\begin{tabular}{|l|l|l|}
\hline \multicolumn{1}{|c|}{$\mathbf{F}_{\mathbf{i}}$} & $\begin{array}{l}\text { Factors Contributing to } \\
\text { Complexity }\end{array}$ & $\mathbf{W}_{\mathbf{i}}$ \\
\hline $\mathbf{F 1}$ & Distributed systems. & $\mathbf{2}$ \\
\hline $\mathbf{F 2}$ & $\begin{array}{l}\text { Application performance objec- } \\
\text { tives, in either response or } \\
\text { throughput. }\end{array}$ & $\mathbf{1}$ \\
\hline F3 & End user efficiency (on-line). & $\mathbf{1}$ \\
\hline F4 & Complex internal processing. & $\mathbf{1}$ \\
\hline F5 & $\begin{array}{l}\text { Reusability, the code must be able } \\
\text { to reuse in other applications. }\end{array}$ & $\mathbf{1}$ \\
\hline F6 & Installation ease. & $\mathbf{0 . 5}$ \\
\hline F7 & Operational ease, usability. & $\mathbf{0 . 5}$ \\
\hline F8 & Portability. & $\mathbf{2}$ \\
\hline F9 & Changeability. & $\mathbf{1}$ \\
\hline F10 & Concurrency. & $\mathbf{1}$ \\
\hline F11 & Special security features. & $\mathbf{1}$ \\
\hline F12 & $\begin{array}{l}\text { Provide direct access for third par- } \\
\text { ties }\end{array}$ & $\mathbf{1}$ \\
\hline
\end{tabular}

\begin{tabular}{|c|c|c|}
\hline F13 & Special user training facilities & 1 \\
\hline F14 & Technological Risks in the project & 1.5 \\
\hline F15 & Multilingual Support in the project & 0.5 \\
\hline F16 & Integration with other systems & 2 \\
\hline F17 & Scalability requirements & 1.5 \\
\hline F18 & Required Software Reliability & 1 \\
\hline F19 & $\begin{array}{l}\text { Documentation (of code and other } \\
\text { technical artifacts) }\end{array}$ & 0.5 \\
\hline F20 & $\begin{array}{l}\text { Use of Third Party API / Pre-build } \\
\text { components }\end{array}$ & -0.75 \\
\hline F21 & $\begin{array}{lr}\text { IDE (Integrated } & \text { Development } \\
\text { Environment) } & \text { supporting } \\
\text { automatic code generation and/or } \\
\text { automatic code introspection }\end{array}$ & -0.25 \\
\hline F22 & $\begin{array}{l}\text { User of Automated testing tool for } \\
\text { testing }\end{array}$ & -0.25 \\
\hline
\end{tabular}


Table 11: New Set of Environmental Factors

\begin{tabular}{|c|c|c|}
\hline $\mathbf{E}_{\mathbf{i}}$ & $\begin{array}{l}\text { Environmental Factors } \\
\text { Contributing to Complexity }\end{array}$ & $\overline{\mathbf{W}_{\mathrm{i}}}$ \\
\hline F1 & Familiar with Application Domain & 1.5 \\
\hline F2 & Part time workers & -1 \\
\hline F3 & Analyst capability & 0.5 \\
\hline F4 & Application experience & 0.5 \\
\hline F5 & Object oriented experience & 1 \\
\hline F6 & Motivation & 1 \\
\hline F7 & Difficult programming language & -1 \\
\hline F8 & Stable requirements & 2 \\
\hline F9 & $\begin{array}{l}\text { Lack of stakeholder (sponsor, } \\
\text { subcontractor etc.) collaboration }\end{array}$ & -1 \\
\hline F10 & $\begin{array}{l}\text { Distractions for the Development } \\
\text { Team }\end{array}$ & -0.25 \\
\hline F11 & Geographically Dislocated team & -0.5 \\
\hline F12 & Project Manager's Capability & 2 \\
\hline F13 & $\begin{array}{l}\text { Testing team's experience with } \\
\text { testing tools \& methodologies }\end{array}$ & 0.5 \\
\hline F14 & $\begin{array}{l}\text { Testing team's experience with } \\
\text { the application / project domain }\end{array}$ & 1 \\
\hline
\end{tabular}

\subsection{Differentiating Estimation of Reports}

\section{from Use Cases}

From the survey $92 \%$ of the respondents agreed that reports should be estimated differently from use cases. It is worth noting that there have been studies [4] that have proposed estimation of reports separately from the use cases however the survey carried as part of this study also identified the complexity scale of the reports that could be used to estimate the required effort to develop reports.

Table 12: Reports Complexity Level

\begin{tabular}{|l|l|l|l|}
\hline & Report Description / Complexity & $(1-10)$ & $\begin{array}{l}\text { Complexity } \\
\text { Factor }= \\
\text { CF }\end{array}$ \\
\hline 1. & Report based on query from one entity only & 2.32 & 2.3 \\
\hline 2. & $\begin{array}{l}\text { Report based on query from two or more entities (table } \\
\text { join) only }\end{array}$ & 3.42 & 3.4 \\
\hline 3. & $\begin{array}{l}\text { Report based on query with table joins along with inner } \\
\text { queries }\end{array}$ & 4.45 & 4.5 \\
\hline 4. & $\begin{array}{l}\text { Report based on query with table joins along with calls to } \\
\text { one or more user defined database function / stored } \\
\text { procedure }\end{array}$ & 5.61 & 5.6 \\
\hline 5. & $\begin{array}{l}\text { Report based on query with recurring function (due to } \\
\text { recurring dependency of records i.e. each record has a } \\
\text { Foreign Key reference to the table itself) }\end{array}$ & 6.97 & 7 \\
\hline
\end{tabular}

Figure 1: 2D Bar Graph - Report Complexity

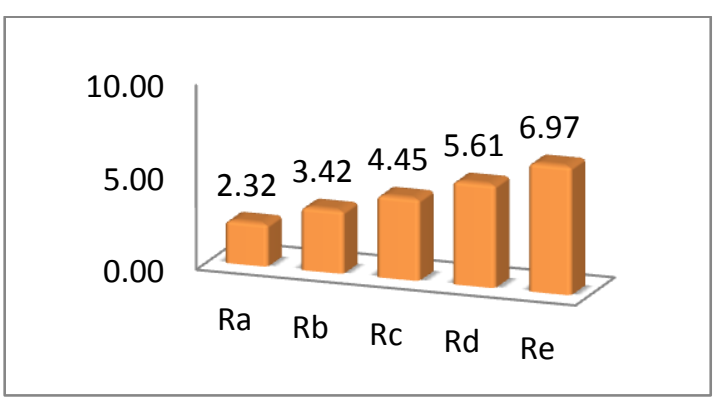

Hence, if the simplest report ('Report based on query from one entity only') requires ' $h$ ' estimated effort with ' $\mathrm{CF}$ ' being the Complexity Factor for a report. From the illustrations above, it signifies that the 'Estimated Effort for Report' (EEF) would be a linear function:

Finally, Estimated Effort for Report (EEF) in man hours = (h / 2.3) $x C F$

\subsection{Estimating the Project Effort based on Project Classification}

COCOMO has been one of the most advanced, widely used and sophisticated estimation model that is used extensively for projects developed using procedural languages. As COCOMO depends on program size, measured in lines of code therefore for projects developed using Object Oriented languages could not be estimated using COCOMO. However the classification of projects defined by COCOMO is irrespective of the programming language paradigm [9], hence the classification of projects by COCOMO makes sense for projects developed using Object Oriented paradigm. And since, UCP model fits for the projects developed using Object Oriented languages [2] therefore the commonality of project classification concept can be used for UCP for improved estimation.

The above notion is supported from the survey results - 76\% of the respondents agreed that the project classification by COCOMO also matters for projects developed using Object Oriented languages [10]; and because UCP model is for object oriented languages therefore the project classification of COCOMO would be considered for UCP model as well.

COCOMO classifies projects into three classes to calculate the Effort with the following formula:

Effort in man months $=a(K L O C)^{b}$

Where the values of variables ' $a$ ' and ' $b$ ' depends on the project classification as follows:

Table 13: Software Projects Classification

\begin{tabular}{|l|l|l|}
\hline Software Projects & a & b \\
\hline Organic & 2.4 & 1.05 \\
\hline Semi-detached & 3.0 & 1.12 \\
\hline Embedded & 3.6 & 1.2 \\
\hline
\end{tabular}

- Organic projects - "small" teams with "good" experience working with "less than rigid" requirements

- Semi-detached projects - "medium" teams with mixed experience working with a mix of rigid and less than rigid requirements 
- Embedded projects - developed within a set of "tight" constraints (hardware, software, operational etc.)

Since, for object oriented languages the concept of KLOC doesn't exist and we could assume KLOC to be constant ' $C$ ' for object oriented languages. As, UCP model does not currently incorporate Software Project Classification therefore, the effort estimated by UCP model would be equivalent to the effort estimated for Organic Projects using COCOMO formula, hence:

$$
\text { Effort in man months }=a(C)^{b}
$$

Hours required per $U C P=H U C P$ (generally it is 20 hours)

Moreover, for UCP Effort in man hours $=U C P * H U C P$

Therefore:

$$
\frac{U C P * H U C P}{30 * 8}=a(C)^{b}
$$

$U C P * H U C P$ is estimated time for organic projects i.e. organic projects as baseline.

In $\left.C=\operatorname{In} U C P-\operatorname{In}\left(\frac{576}{H U C P}\right)\right) / 1.05$

Hence the equation for Base Line Constant for Estimation of projects 'in man hours' is derived to be:

$$
C=e^{\frac{\left(\operatorname{In} U C P-\operatorname{In}\left(\frac{576}{H U C P}\right)\right)}{1.05}}
$$

For $H U C P=20$

$$
C=e^{\left(\frac{\operatorname{In} U C P-3.36}{1.05}\right)}
$$

The above results can be summarized as follows:

Table 14: Estimated Effort Method based on Project Classification

\begin{tabular}{|l|l|l|}
\hline $\begin{array}{l}\text { Software } \\
\text { Projects }\end{array}$ & $\begin{array}{l}\text { Estimated } \\
\text { Effort }\end{array}$ & Description \\
\hline Organic & $U C P * H U C P$ & $\begin{array}{l}\text { UCP is the calculated Use } \\
\text { Case Points and HUCP is } \\
\text { the number of hours } \\
\text { required to implement one } \\
\text { UCP. }\end{array}$ \\
\hline $\begin{array}{l}\text { Semi- } \\
\text { detached }\end{array}$ & $a(C)^{b}$ & $\begin{array}{l}a=3.0, b=1.12 \text { and } \\
\text { C is the baseline constant }\end{array}$ \\
\hline Embedded & $a(C)^{b}$ & $\begin{array}{l}a=3.6, b=1.2 \text { and C } \\
\text { is the baseline constant }\end{array}$ \\
\hline
\end{tabular}

\section{THE EXTENDED UCP MODEL}

From the results of section '4 - Error! Reference source not found.' the extended UCP Model would calculate the estimated effort in four steps:

Step-1: Calculate the UCP using new / extended set of Technical and Environmental Factors.

Step-2: Calculate the Estimated Effort for Reports in man hours.
Step-3: Calculate the Estimated Effort of Project based on Project Classification in man hours.

Step-4: Calculate the Total Estimated Effort in man hours by adding the Estimated Efforts from step-2 and step-3.

\section{CONCLUSION}

Estimating the effort of a software project has always been a difficult task. Several methods of software estimation proposed in the literature before object oriented technology became popular [2]. Since, object oriented approach has become de facto standard for software development; therefore it became necessary to revamp the estimation models to suite the object oriented technology [2]. Karner [1] proposed a method to estimate the effort using use case model which was attractive and suitable [2] but with the ever changing IT industry it became a bit obsolete due to emerging trends in IT industry. The authors of this paper extended Karner's approach by incorporating the current trends in software estimation.

\section{REFERENCES}

[1] Karner, Gustav. Metics for Objectory. Diploma Thesis, University of Linkoping, Sweden. No. LiTHIDA-Ex93441:21. December 1993

[2] Kasi Periyasmay and Aditi Ghode. Cost Estimation using extended Use Case Point (e-UCP) Model .IEEE

[3] Kasunic, M. 2005. Designing an Effective Survey. Technical Handbook. Pittsburg: Software Engineering Institute. Carnegie Mellon University. September, 2005

[4] Carroll, Edward R., Estimating Software Based on Use Case Points. Agilis Solutions, A Business Unit of Hepieric, Inc. ACM. October 2005

[5] Boehm, B., Software Engineering

[6] Krintin \& Monika "software effort estimation as collective accomplish: an analysis of estimation practice in a multi specialist team" http://iris.cs.aau.dk/tl_files/volumes/Volume22/no2/5Bor te.pdf

[7] David Hoyle (2012): ISO 9000 Quality Systems Handbook; Fifth edition

[8] Mary Beth, Mike Konrad, Sandra Shrum., CMMI for development: Guideline for process integration and product Improvement, 2011

[9] Allen B. Tucker: Programming languages Principles and Paradigms, 2001

[10] M. Nadeem, M R Asim and M R J Quershi “ A step forward to component based software cost estimation in object oriented environment" http:// arxiv.org/ftp/arxiv/papers/1202/1202.2511.pdf

[11] Mange and Stein "software development effort estimation: Demystifying and improving expert estimation"

http://simula.no/research/se/publications/Simula.SE.427/ simula_pdf_file 